ORIGINAL CONTRIBUTIONS 
Brandeis University, Waltham, Massachusetts

Rosenstiel Research Center, Department of Biology

(Director: Dr. H. O. Halvorson)

\title{
THE REPERTOIRE OF ANTIBODIES TO A HAPTEN GROUP IN AN INBRED STRAIN OF MOUSE *
}

\author{
Shyr-Te Ju Alfred Nisonoff
}

One of the most interesting questions in immunology concerns the basis of the diversity of the structures of antibodies. It is generally accepted that the number of antibody molecules that can be produced by an individual animal, or more specifically by a given inbred strain of mouse, is extremely large. For example, KRETH and WILLIAMSON ${ }^{12}$ estimate that CBA mice are capable of producing at least 8,000 different antibody molecules with binding specificity for the 3-nitro-4-hydroxy-5-iodophenacetyl hapten group. The basis for this conclusion is the number of spectrotypes (isoelectric focusing patterns) associated with these particular anti-hapten antibodies in the CBA strain. Another example of the extreme diversity of antibodies was provided by the early work of EISEN and SISKIND ${ }^{5}$ who showed that antibodies to the dinitrophenyl hapten group, produced in an individual rabbit, may have binding affinities ranging from $10^{5}$ to $10^{9} \mathrm{M}^{-1}$. We will in this paper provide further data illustrating the great diversity of antibodies to a single hapten group that can be synthesized by mice of an inbred strain. The methods employed appear to be considerably more sensitive than those previously used.

Two major types of experimental evidence have been used in constructing hypotheses to explain the generation of antibody diversity. One consists of amino acid sequence analysis of monoclonal proteins associated with malignancy or generated by certain immunization procedures; prime examples of the latter approach come from the laboratories of Richard Krause and Edgar Haber, who have worked

Key-words: Antibody diversity; Antibody repertoire; Idiotype frequency; Idiotypes; Idiotypic suppression; Somatic mutation.

* This work was supported by grants from the US National Institutes of Health (AI-12907, AI-12908, and AI-12985).

Accepted for publication on August 29, 1977.

La Ricerca Clin. Lab. 7, 331, 1977. 
with homogeneous induced antibodies directed to streptococcal and pneumococcal polysaccharides, respectively.

A second source of information are studies of the hybridization of mRNA for immunoglobulin polypeptide chains with the DNA of lymphoid or non-lymphoid cells; hybridization studies have also been carried out with cDNA prepared by reverse transcription of the $m R_{N A}{ }^{14,19,22,23}$. Very recently, successful attempts have been made to clone portions of the mouse genome containing DNA specific for immunoglobulin polypeptides, using restriction enzymes to obtain segments of the DNA for cloning (ToNEgawA, personal communication). Sequences of the DNA segments are also being obtained by Tonegawa, Gilbert, Maxam and their collaborators, and one may expect substantial progress in this area in the near future.

Starting with the first published V region sequences by HilsCHMANN and CRAIG in $1965^{8}$, a number of theories have been devised to account for the diversity of sequences, particularly in the variable regions. It is now generally agreed that separate genes, $V$ and $C$, encode the variable and constant regions of each polypeptide chain. For a synopsis of data leading to this hypothesis, the reader is referred to Nisonoff et al. ${ }^{16}$.

Although there are a number of specific theories, they may be conveniently broken down into two major classifications: the multiple germ-line gene theory and that of somatic diversification. The former presupposes that all information for antibody production is encoded in the germ-line and is inherited. The latter assumes that there are a limited number of germ-line genes and that these are diversified during the lifetime of the individual by some somatic process, such as point mutations, recombination or introduction of errors into the sequence, followed by repair to yield a new set of codons. A variation of these theories assumes that there are separate genes coding for the hypervariable segments of each polypeptide chain which are inserted into the gene encoding the non-hypervariable (framework) portion of each V region (the so-called 'episomal insertion' theory) ${ }^{26}$. This might be considered as a variation of the multiple germ-line theory.

During the past 2 or 3 years major constraints have been placed on these theories by studies of hybridization of mRNA, derived from myeloma tumours, or its complementary cDNA, with the DNA of a variety of cells, including myeloma and normal cells ${ }^{16,26}$. The results of these studies are consistent in indicating that there is a very small number of DNA sequences that will hybridize under stringent conditions with a particular messenger RNA or its reverse DNA transcript. It is generally believed that there are less than five genes for each subgroup of $V$ genes. A subgroup may be roughly defined as a group of light chains which show more than $80 \%$ homology in their V region sequences. Recently, greatest attention has been focused on mouse $\lambda$ chains since the amino acid sequences obtained so far indicate that most mouse $\lambda$ chains fall into a single subgroup. Hybridization data ${ }^{22}$ suggest, again, that there are less than five copies of this DNA sequence in any cell, but the amino acid sequence data would suggest that there must be at least 25 sequences and that number may conceivably be much larger. These data are difficult to reconcile with a strict germ-line theory and argue for a somatic process of diversification. In the case of mouse $x$ chains the number of subgroups is probably quite large and it is difficult to draw firm conclusions from hybridization data for this reason. Again, however, hybridization studies indicate that there is a very small number of germline genes for each $V$ region subgroup. Most immunologists now feel that the multiple 
germ-line gene theory is on the defensive. Techniques of cloning of large DNA segments by recombination methods, followed by DNA sequence analyses, are now being applied and may resolve this question.

Data we will present here suggest that: 1) the diversity of anti-hapten antibodies of a given specificity with a single strain of mouse is extremely large; the techniques we have applied are considerably more sensitive than the method of spectrotyping (based on isoelectric focusing); 2) on the basis of these data, we have drawn the tentative conclusion that the generation of diversity is associated with a random process of somatic mutation, rather than a programmed, genetically controlled series of mutations. Most of the results discussed here have recently been published ${ }^{9}$. However, we will attempt to discuss the implications of the results in considerable detail.

In order to introduce the principle of the method employed, it is necessary to provide some historical background. The system we use involves antibodies to the $p$-azophenylarsonate hapten group (anti-Ar antibodies) produced in strain A mice. Some years ago it was found in this laboratory that every $\mathrm{A} / \mathrm{J}$ mouse, when immunized with a conjugate of keyhole limpet haemocyanin with the Ar hapten group $(\mathrm{KLH}-\mathrm{Ar})$, produces anti-Ar antibodies, some of which share idiotype with the corresponding antibodies of all other mice of the A strain ${ }^{13}$. The proportion of the anti-Ar antibody population which carries this idiotype in an individual mouse generally varies from about $20-70 \%$; the cause of this variability is not known, but it may simply be due to the probability of triggering lymphocytes with the particular idiotypic specificity. In any event, the fact that the idiotype appears in all mice of the A strain has made it useful as a marker in a variety of genetic and structural studies ${ }^{18}$.

The presence of the idiotype in serum or ascitic fluids is detected by a radioimmunoassay ${ }^{13}$. This assay utilizes, as ligand, ${ }^{125} \mathrm{I}$-labeled specifically purified anti-Ar antibodies carrying the cross-reactive idiotype (CRI). Typically $10 \mathrm{ng}$ are used in each test. This is mixed with rabbit serum containing an amount of anti-idiotypic antibodies that represent slightly less than an excess over the amount of labeled ligand present. Because of the very small amount of antigen present, this mixture will not form a precipitate; however, soluble complexes are formed. The complexes are precipitated by adding a small amount of normal rabbit serum (sufficient to provide $30-40 \mu \mathrm{g}$ of $\mathrm{IgG}$ ) followed by a goat antiserum containing an excess of antibodies specific for the Fc portion of rabbit IgG. This brings down all of the rabbit IgG present and, if any of the radiolabeled ligand is bound to rabbit antibody, it will also be incorporated in the precipitate. If anti-idiotypic antibodies are absent from the rabbit serum, the precipitate will be essentially devoid of radioactivity. The presence of the idiotype can now be detected in unlabeled samples by measuring their ability to compete with the labeled ligand for the limited amount of rabbit anti-idiotypic antibodies present. If, for example, one adds $1,000 \mathrm{ng}$ of unlabeled anti-Ar antibodies bearing the cross-reactive idiotype (CRI) they will effectively displace the radiolabeled ligand because of the insufficiency of rabbit anti-idiotypic antibodies present. The degree of displacement would be approximately $99 \%$. Using this principle, it is possible to detect and quantitate the idiotype in unlabeled preparations, such as serum or ascites. The quantitation is done by comparing the degree of displacement with that caused by a known weight of anti-Ar antibodies carrying the idiotype. 
A second radioimmunoassay is used to quantitate the total amount of anti-Ar antibodies (with or without the idiotype) in an unknown sample. This is based on a method devised by KLINMAN et al. ${ }^{10}$. It makes use of polyvinyl microtiter plates which contain 96 wells, each capable of holding approximately $0.4 \mathrm{ml}$ of liquid. As a first step the wells are exposed to a solution of bovine serum albumin conjugated with the phenylarsonate $(\mathrm{Ar})$ hapten group. A small amount of this antigen becomes irreversibly bound through non-covalent forces to the polyvinyl surface. After extensive washing the wells are then exposed to $2 \%$ horse serum to saturate the 'binding sites' on the polyvinyl surface. However, the surfaces of the wells are now capable of binding anti-Ar antibodies, and the amount bound will be a function of the concentration of these antibodies in an unknown sample (serum or ascites). After exposing the well to the fluid containing anti-Ar antibodies for several hours it is again washed, and a solution containing specifically purified, ${ }^{125} \mathrm{I}$-labeled rabbit anti-mouse $\operatorname{IgG}$ is added. After standing and washing, the individual wells are then cut out and the radioactivity is determined. The amount of radioactivity bound will depend on the amount of mouse anti-Ar antibodies that had been adsorbed by the previous exposure to the unknown sample; i.e., the amount of radioactivity will be proportional to the concentration of anti-Ar antibodies in the unknown sample. With each run, standards are included which contain known concentrations of anti-Ar antibodies; the concentration of antibodies in the unknown is determined with the aid of a standard curve constructed by using the data obtained with these known samples. The two radioimmunoassays described above are the basic analytical techniques used in the studies to be described.

Another method used in these investigations is the development of ascitic fluids containing anti-Ar antibodies ${ }^{24}$. The method consists of multiple injections of the antigen emulsified in complete Freund's adjuvant. It is essential to use a 9:1 volume ratio of adjuvant to antigen solution in order to induce ascites. The antibodies in ascitic fluids are in equilibrium with the antibodies in the serum of the animal. The development of ascitic fluids has the advantage that large amounts of antibodies can be obtained, since as much as $10-15 \mathrm{ml}$ of fluid can be tapped over a period of time from an individual mouse. Antibody concentrations are comparable to those of hyperimmune sera.

Another earlier finding which forms the basis for the present work was the discovery that the appearance of the cross-reactive idiotype (CRI) normally associated with the anti-Ar antibodies of strain A mice, can be suppressed simply by inoculating a mouse with rabbit anti-idiotypic antiserum prior to initiating the series of injections with $\mathrm{KLH}-\mathrm{Ar}^{7,17}$. Such mice produce normal concentrations of anti-Ar antibodies, but they lack the cross-reactive idiotype. The initial mechanism of suppression probably involves deletion of the clones of cells producing the idiotype. However, after immunization with KLH-Ar, the suppressed mice develop substantial concentrations of suppressor $T$ cells which can adoptively transfer the suppressed state to mildly irradiated recipient $\mathrm{A} / \mathrm{J}$ mice ${ }^{25}$.

Soon after developing the method of suppression we asked the question whether anti-idiotypic antibodies could be prepared against the anti-Ar antibodies of mice that had been suppressed with respect to the CRI ${ }^{6}$. No difficulty was experienced in producing such anti-idiotypic antisera, which of course have no relationship in their specificity to the anti-idiotypic antisera reactive with the CRI. However, we could now ask the question whether the new idiotypes arising in the suppressed 
mice could also be found in other immunized A/J mice, either suppressed or nonsuppressed with respect to the CRI. The answer was negative. Very low or undetectable concentrations of these idiotypes could be found in other mice. Thus, it appeared that the individual idiotypes appearing in the suppressed animals were specific for the individual mice.

This approach, however, possessed one serious defect. The anti-Ar antibodies of an individual suppressed mouse undoubtedly comprise a spectrum of idiotypes. It was conceivable that one or more of these idiotypes, arising in a suppressed mouse, might actually be present in other immunized mice but incapable of causing $50 \%$ inhibition in the radioimmunoassay because of the heterogeneity of the radioactive ligand. If there were, for example, ten significant idiotypes in the anti-Ar antibodies of a suppressed mouse, the serum of another mouse that produced only one of these ten idiotypes might cause only $10 \%$ inhibition of binding; and one would draw the erroneous conclusion that the idiotypes studied were unique to the individual suppressed mouse.

\section{MATERIALS AND METHODS}

In order to circumvent the diffculty described above, the anti-Ar antibodies of individual suppressed mice were specifically purified and subjected to isoelectric focusing on a semipreparative scale ${ }^{9}$. The method utilized polyacrylamide gels, $5 \times 115 \mathrm{~mm}$. After focusing, the gels were subdivided and extracted with a Savant Autogel Divider. Approximately 130-150 fractions were obtained from each gel. Every fourth fraction was used for the determination of $\mathrm{pH}$, whereas the other fractions were available for analytical examination. For use in the radioimmunoassay for the 'private idiotypes' of suppressed mice, single major peaks were used as the radioactive ligand. Another criterion for the use of an individual peak was that more than $90 \%$ of the protein in the peak was precipitable with the anti-idiotypic antiserum. Control experiments were carried out to show that each of the peaks selected refocused with the same pI (isoelectric pH) value when subjected to a second analysis. We were therefore confident that the protein being used as radioactive ligand in the assay for idiotype represented a very small number of idiotypes and probably only one.

To maximize the sensitivity of detection of these idiotypes in other mice, a minimal amount of radioactive ligand, generally $2 \mathrm{ng}$, was used in each assay. A total of 4 individual idiotypes, obtained from three suppressed mice, was used. These were obtained from randomly selected, suppressed $\mathrm{A} / \mathrm{J}$ mice that had produced high concentrations of anti-Ar antibodies lacking the CRI.

To test for the presence of each of these four private idiotypes in other mice, a panel of $181 \mathrm{~A} / \mathrm{J}$ mice was used. Each of these mice had been hyperimmunized with $\mathrm{KLH}-\mathrm{Ar}$ and its total anti-Ar antibody content determined by the radioimmunoassay using polyvinyl microtiter plates. Of these 181 mice, 37 had been suppressed with respect to the common CRI whereas the remainder of the mice were non-suppressed. (It should be noted that even non-suppressed mice produce 30 to $80 \%$ of anti-Ar antibodies lacking the CRI).

\section{RESULTS}

Fig. 1 shows the isoelectric focusing pattern of the specifically purified anti-Ar antibodies of mouse HIS-5 which had been suppressed with respect to the CRI and then hyperimmunized ${ }^{9}$. Anti-Ar antibodies from two of the peaks, with pI values of 6.3 and 6.9 , were selected for further study. Fig. 2 shows the refocusing pattern of the two peaks with pI values of 6.3 and 6.9. Three times as much of the former material was used in order to facilitate identification in the refocusing pattern. It is evident that both proteins refocused as a single major peak. The $\mathrm{pI}$ values agreed 


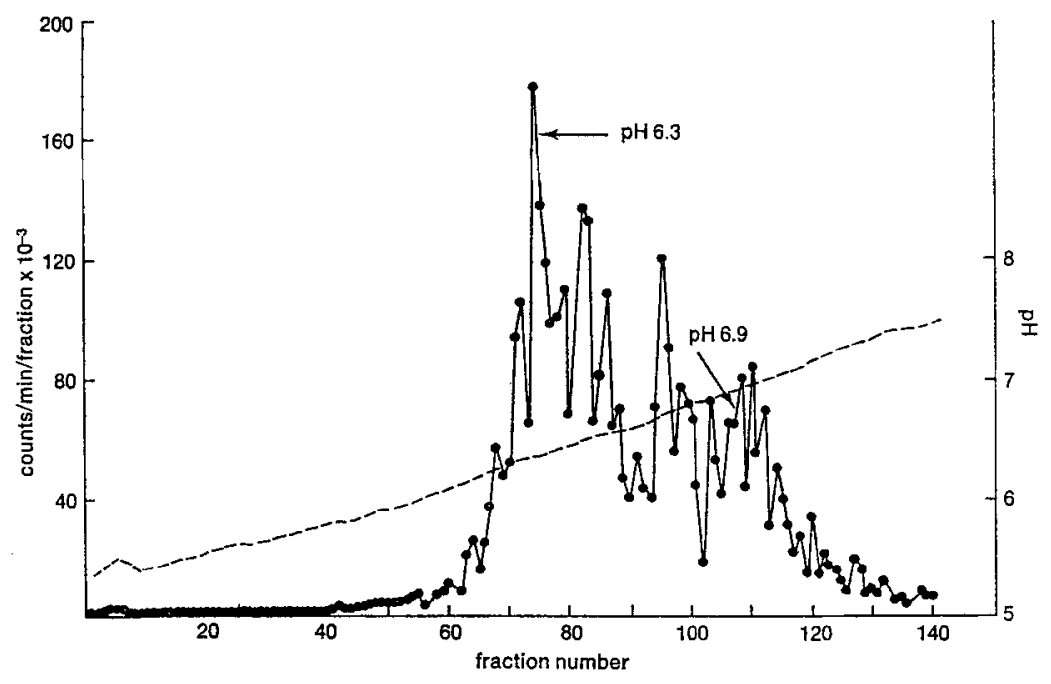

Fig. 1 - Isoelectric focusing pattern of the specifically purified anti-Ar antibodies of mouse HIS-5. The mouse had been suppressed with respect to the common cross-reactive idiotype and then hyperimmunized, prior to the purification of anti-Ar antibodies from hyperimmune ascitic fluid. The antibodies were labeled with ${ }^{225} \mathrm{I}$ to permit subsequent radioimmunoassays, utilizing as ligands labeled proteins in the two peaks specified on the figure $(\mathrm{pH} 6.3$ and $\mathrm{pH} 6.9)$. The dashed line represents the isoelectric $\mathrm{pH}$. The fractions were obtained with a Savant Autogel Divider.

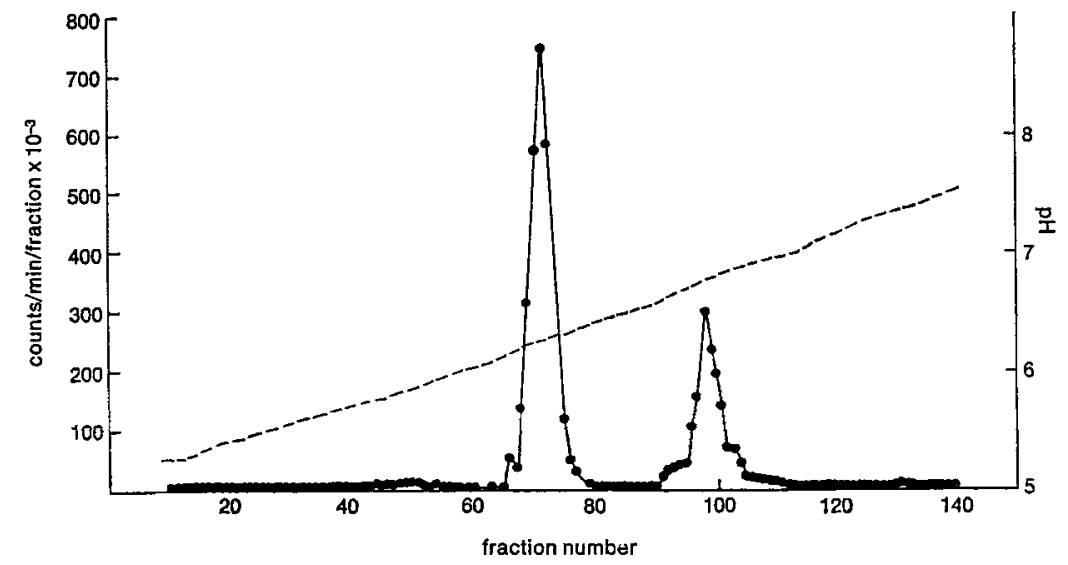

Fig. 2 - Refocusing patterns of the two peaks designated by arrows in fig. 1 (pI 6.3 and 6.9). Three times as much of the former protein was used in order to facilitate identification. The proteins in the two peaks refocused with $\mathrm{pI}$ values agreeing within $0.05 \mathrm{U}$ with those observed in the first run (fig. 1). 


\begin{tabular}{l|c|c}
\hline $\begin{array}{l}\text { inhibitors } \\
\text { (sources of anti-Ar antibodies) }\end{array}$ & $\begin{array}{c}\text { no. of } \\
\text { mice }\end{array}$ & $\begin{array}{c}\text { ng of anti-Ar antibody } \\
\text { required for } 50 \% \text { inhibition * }\end{array}$ \\
\hline $\begin{array}{l}\text { autologous (HIS-7, specifically } \\
\text { purified) }\end{array}$ & & 8 \\
& 5 & $>10,000$ \\
non-suppressed A/J mice & 71 & $>25,000$ \\
& 68 & $>75,000$ \\
& 14 & $>10,000$ \\
A/J mice suppressed for CRI & 13 & $>75,000$ \\
& 10 & \\
\hline
\end{tabular}

* $1.5 \mathrm{ng}$ of labeled ligand was used in the assay.

Tab. 1 - Displacement from anti-idiotypic antibody of the major peak (pI 6.7) of the anti-Ar antibody of the suppressed, hyperimmunized mouse HIS-7.

within $0.05 \mathrm{U}$ with those observed in the original determination (fig. 1). The data obtained with these two proteins will be discussed below.

Tab. 1 shows the results obtained when a major peak ( $\mathrm{pI}$ 6.7) from the anti-Ar antibodies of another suppressed $A_{/}^{\prime} \mathrm{J}$ mouse, HIS-7, was used as the labeled ligand. The anti-idiotypic antibodies had been prepared against the anti-Ar antibodies of this mouse. The data in tab. 1 show the results obtained when efforts were made to find this idiotype in the panel of 181 immunized $\mathrm{A} / \mathrm{J}$ mice described above. It is evident that, despite the great sensitivity of the method, this idiotype could not be detected in ascitic fluids containing antibodies from any one of the 181 mice tested. Whereas $8 \mathrm{ng}$ of unlabeled antibody from mouse HIS-7 caused $50 \%$ inhibition of binding, this degree of inhibition could not be obtained with the largest amounts of antibodies from any of the other mice tested (up to 200,000 ng). Thus the concentration of the idiotype ranges from less than 1 part in 1,200 to 1 part in 25,000 of the total anti-Ar antibody concentration. In nearly all instances, the maximal degree of inhibition observed was less than $20 \%$ and the value never approached $50 \%$. It therefore appears that the idiotype characteristic of the major peak of the anti-Ar antibodies of mouse HIS-7 was not present in any of the 181 mice tested.

The possibility was considered that the idiotype of mouse HIS-7 might have been present in one or more of the panel of 181 mice but was masked by some agent present in the ascitic fluid, through chemical interaction or some other mechanism. To provide data relevant to this question the following experiments were performed. A small amount (10 ng) of unlabeled anti-Ar antibody from mouse HIS-7 was added to $25 \mu \mathrm{l}$ of ascitic fluid from each of 20 randomly selected mice which had been non-inhibitory in the tests described in tab. 1. In each case the mixture now caused more than $50 \%$ inhibition of binding in the radioimmunoassay. This experiment proves that the failure to detect the idiotype was not due to some factor masking its presence. This experiment was repeated in another system, described below, namely that associated with the antibodies of mouse HIS-5 (pI 6.9 fraction). The results obtained were identical. 
The data in tabs 2 and 3 show results obtained with the private idiotypes of 2 other mice, suppressed for the CRI and then immunized: HIS-13 (pI 6.9 peak) and HIS-5 (pI 6.9). As shown in tab. 2, none of the ascitic fluids from the 181 mice were able to cause $50 \%$ inhibition of binding of the protein from mouse HIS-13 to its anti-idiotypic antibodies; i.e., the idiotype was not detectable in any of these

\begin{tabular}{l|c|c}
\hline $\begin{array}{l}\text { inhibitors } \\
\text { (sources of anti-Ar antibodies) }\end{array}$ & $\begin{array}{c}\text { no. of } \\
\text { mice }\end{array}$ & $\begin{array}{c}\text { ng of anti-Ar antibody } \\
\text { required for 50\% inhibition * }\end{array}$ \\
\hline $\begin{array}{l}\text { autologous (HIS-13, specifically } \\
\text { purified) }\end{array}$ & & 85 \\
\multicolumn{1}{c|}{ unfocused } & & 15 \\
\multicolumn{1}{c|}{ focused } & 5 & $>10,000^{* *}$ \\
non-suppressed A/J mice & 71 & $>25,000$ \\
& 68 & $>75,000$ \\
A/J mice suppressed for CRI & 14 & $>10,000$ \\
& 13 & $>75,000$ \\
\hline
\end{tabular}

* $2 \mathrm{ng}$ of labeled ligand were used in the assay;

$\because *$ these numbers are the same as those in tab. 1 because the same 181 samples were used in the test.

Tab. 2 - Displacement of labeled anti-Ar antibodies of A/J mouse HIS-13 (pI 6.9) from their anti-idiotypic antiserum.

\begin{tabular}{l|c|c}
\hline $\begin{array}{l}\text { inhibitors } \\
\text { (sources of anti-Ar antibodies) }\end{array}$ & $\begin{array}{c}\text { no. of } \\
\text { mice }\end{array}$ & $\begin{array}{c}\text { ng of anti-Ar antibody } \\
\text { required for } 50 \% \text { inhibition * }\end{array}$ \\
\hline autologous (HIS-5, specifically & & \\
purified) & & 50 \\
\multicolumn{1}{c|}{ unfocused } & & 15 \\
$\quad$ focused (pI 6.9) & & $>135$ \\
& 1 & 4,400 \\
& 2 & $40,000,100,000$ \\
& 4 & $>10,000$ \\
non-suppred (pI 6.3) & 70 & $>25,000$ \\
& 67 & $>75,000$ \\
& 14 & $>10,000$ \\
A/J mice suppressed for CRI & 13 & $>75,000$ \\
& 10 & \\
total no. of mice tested & 181 & \\
\hline
\end{tabular}

* $1.5 \mathrm{ng}$ of labeled ligand was used in the assay.

Tab. 3 - Displacement of labeled anti-Ar antibodies of A/J mouse HIS.5 (pI 6.9) from their anti-idiotypic antiserum. 


\begin{tabular}{l|c|c}
\hline $\begin{array}{l}\text { inhibitors } \\
\text { (sources of anti-Ar antibodies) }\end{array}$ & $\begin{array}{c}\text { no. of } \\
\text { mice }\end{array}$ & $\begin{array}{c}\text { ng of anti-Ar antibody } \\
\text { required for } 50 \% \text { inhibition * }\end{array}$ \\
\hline $\begin{array}{l}\text { autologous (HIS-5, specifically } \\
\text { purified) }\end{array}$ & & 37 \\
unfocused & & 8 \\
focused (pI 6.3) & & $>70$ \\
& 3 & $800,1,400,2,000$ \\
non-suppressed A/J mice & 18 & 300 to 10,000 \\
& 25 & 11,000 to 120,000 \\
& 5 & $>10,000$ \\
& 49 & $>25,000$ \\
& 44 & $>75,000$ \\
A/J mice suppressed for CRI & 2 & $3,000,10,000$ \\
& 13 & 11,000 to 150,000 \\
total no. of A/J mice tested & 10 & $>10,000$ \\
& 9 & $>75,000$ \\
\hline
\end{tabular}

* $1.5 \mathrm{ng}$ of labeled ligand was used in the assay.

Tab. 4 - Displacement of labeled anti-Ar antibodies of A/J mouse HIS-5 ( $\mathrm{pI} 6.3$ ) from their anti-idiotypic antiserum.

mice. Thus, the private idiotypes of mice HIS-7 and HIS-13 were undetectable or absent in each of the 181 ascitic fluids tested. In the case of mouse HIS-5 (pI 6.9), three of the ascitic fluids tested did cause $50 \%$ inhibition, but the amounts of anti-Ar antibodies required were extremely large as compared to the amounts of autologous unlabeled protein that were necessary.

In the case of the fourth protein studied, anti-Ar antibodies from mouse HIS-5, pI 6.3 fraction, the idiotype was found in a substantial number of the ascitic fluids tested as inhibitors (tab. 4). Fifty-one, or $28 \%$ of these fluids, did cause $50 \%$ inhibition. However, in each case the weight of anti-Ar antibodies required was far greater than that of the autologous (HIS-5) unlabeled anti-Ar antibodies.

\section{DISCUSSION}

The results summarized here demonstrate a striking contrast between the crossreactive idiotype (CRI) which is found in every mouse of the $A / J$ strain that is immunized with KLH-Ar, and the private idiotypes arising in suppressed mice, which in three of four instances were virtually impossible to detect in any other mouse. We believe that the simplest interpretation of these findings is that the CRI represents the product of a germ-line gene or genes, or of genes arising through a 
very small number of mutational events which take place in every $\mathrm{A} / \mathrm{J}$ mouse. It is, of course, difficult to see a teleological advantage in the preservation of germ-line genes coding for an antibody to the phenylarsonate group which, it would appear, might have little bearing on the survival of the mouse. However, in view of the very large size of the hypervariable region it is by no means inconceivable that a given molecule might have more than one specificity. This possibility has been stressed by others, in particular EISEN et al. ${ }^{4}$ and RiCHARDS et al. ${ }^{20}$. The anti-Ar antibodies bearing the CRI may have an additional, more useful specificity of which we are presently unaware. Another possibility is that some structure on a bacterial or viral surface may resemble in its contours the phenylarsonate group. This is true of the phosphorylcholine group which appears to be component of the cell walls of certain bacteria ${ }^{21}$, and which induces the formation of antibodies with a cross-reactive idiotype in $\mathrm{BALB} / \mathrm{c}$ mice ${ }^{2}$ and certain other strains.

We would attribute the very low frequency of the private idiotypes arising in suppressed mice to their generation through a rather large number of mutational or recombinational events, which would have a low probability of recurrence in other mice. This would be true of three of the four idiotypes tested, which could not be detected in all or nearly all of the panel of mice tested for the inhibitory capacity of their anti-Ar antibodies. It should be stressed that the germ-line gene from which these private idiotypes arose through mutation is not necessarily that associated with the production of the CRI found in all $\mathrm{A} / \mathrm{J}$ mice. A variety of germ-line genes might serve as precursors for the genes which ultimately produce anti-Ar antibodies with private idiotypes.

One idiotype, namely that of mouse HIS-5 (pI 6.3) was found in low levels in $28 \%$ of the mice investigated. Our hypothesis would account for this by assuming that this idiotype can arise from a germ-line gene by a limited number of mutational events, which would have a reasonable probability of occurrence in other mice. Other experiments, not shown here, indicated that the inhibitory capacity, in seven of ten mice tested, was entirely attributable to the anti-Ar antibodies in the ascitic fluids. This inhibitory capacity was therefore probably associated with an idiotype either similar or identical to that of the autologous mouse, HIS-5.

A point worth stressing is the great sensitivity of the methods used, which are far more sensitive than the analysis of spectrotypes obtained by isoelectric focusing. Whereas 8 to $30 \mathrm{ng}$ of the autologous, unlabeled protein was capable of causing $50 \%$ inhibition in the radioimmunoassay, thousands of ng of anti-Ar antibodies from other mice were non-inhibitory, the ratio of the two values is minimal since $50 \%$ inhibition of binding was not approached in most instances. The results emphasize the enormous diversity of antibodies to a single hapten group that can be formed by mice of the A strain.

While our data do not prove this point, we feel that they are consistent with a random rather than a programmed system of somatic mutations. Programmed mutations have been proposed by others on the basis of the appearance of certain specificities or idiotypes at apparently defined periods of time within the life span of mice of a given strain ${ }^{3,11,15}$. It should be noted, however, that the appearance of a particular idiotype might reflect the 'turning on' of a germ-line gene rather than a programmed series of mutation. The appearance of certain specificities (rather than idiotypes) at a relatively fixed point in the life span of a mouse might be attributable to the activation of germ-line genes at particular times or to the formation of anti- 
bodies of the specificity studied at relatively defined periods, because of the activation of germ-line genes which in turn are capable of giving rise to the specificity in question after undergoing somatic mutations. Finally, we have used the phrase 'somatic mutation' as a general term to indicate a process influencing the structure of genes controlling $\mathrm{V}$ regions of immunoglobulins. Such a process might include recombination, excision and repair, or other modifications of DNA, as well as the most obvious type of modification, namely point mutation. There is at present no direct evidence to substantiate the precise mechanisms involved in the generation of diversity.

\section{SUMMARY}

We have investigated the diversity of antibodies to the $p$-azophenylarsonate (Ar) hapten group in the A strain of mouse. The method used consisted of suppressing an idiotype which commonly is observed in the anti-Ar antibodies of all mice of this strain, and then generating anti-idiotypic antisera against the anti-Ar antibodies (lacking the cross-reactive idiotype) which arose after hyperimmunization of the suppressed mice. Anti-idiotypic antibodies prepared against these anti-Ar antibodies were used as a tool to investigate the frequency of recurrence of individual idiotypes in other mice of the same strain. A highly sensitive radioimmunoassay indicated that 3 of the 4 idiotypes studied were virtually undetectable in a panel of $181 \mathrm{~A} / \mathrm{J}$ mice immunized against the phenylarsonate hapten. A fourth idiotype was found but at very low frequency. The results emphasize the enormous diversity of the immune response to a single hapten group within a strain of mouse. They ate interpreted on the basis of a hypothesis that the diversity arises through a random series of somatic events. The common cross-reactive idiotype, which is present in the anti-Ar antibodies of all normal $\mathrm{A} / \mathrm{J}$ mice, is postulated to be the product of a germ-line gene or of a gene which is closely related to a germ-line gene through a small number of somatic mutations which takes place in every $\mathrm{A} / \mathrm{J}$ mouse.

\section{REFERENCES}

1) Capra J.D., Kindt T. J.: Antibody Diversity: Can More than One Gene Encode Each Variable Region? - Immunogenetics 1, 417, 1975.

2) Cohn M., Notani G., Rrce S.A.: Characterization of the Antibody to the C-Carbohydrate Produced by a Transplantable Mouse Plasmacytoma - Immunochemistry 6, 111, 1969.

3) D’Eustachio P., Cohen J.E., Edelman G. M.: Variation and Control of Specific AntigenBinding Cell Populations in Individual Fetal Mice - J. exp. Med. 144, 79, 1976.

4) Eisen H. N., Michaelides M. C., Underdotin B. J., Schulenderg E. P., Simms E. S.: Myeloma Proteins with Antihaptens Antibody Activity - Fed. Proc. 29, 78, 1970.

5) EISEN H.N., Srskind G.W.: Variations in Affinities of Antibodies during the Immune Response - Biochemistry 3, 996, 1964.

6) HART D. A., PAwLAK L.L., NIsonoff A.: Nature of Antihapten Antibodies Arising after Immune Suppression of a Set of Cross-Reactive Idiutypic Specificities - Europ. J. Immunol. $1,44,1973$.

7) Hart D. A., Wang A. L., PAwLak L. L., Nisonoff A.: Supptession of Idiotypic Specificities in Adult Mice by Administration of Anti-Idiotypic Antibody - J. exp. Med. 135, 1293, 1972.

8) Hirlschmann N., Cratg L. C.: Amino Acid Sequence Studies with Bence Jones Proteins Proc. nat. Acad. Sci. (Wash.) 53, 1403, 1965.

9) Ju S.-T., Gray A., Nisonofr A.: Frequency of Occurrence of Idiotypes Associated with Anti-p-Azophenylarsonate Antibodies Arising in Mice Immunologically Suppressed with Respect to a Cross-Reactive Idiotype - J. exp. Med. 145, 540, 1977.

10) Klinman N. R., Pickard A.R., Sigal N.H., Gearhart P. J., Metcalf E. S., Pierce S. K.: Assessing B Cell Diversification by Antigen Receptor and Precursor Cell Analysis - Ann. Inst. Pasteur 127C, 489, 1976.

11) Klinman N.R., Press J. L., Stgal N. H., Gearhart P. J.: The Acquisition of the B Cell Specificity Repertoire: The Germ-Line Theory of Predetermined Permutation of Genetic Information - In: CunNINGHAM A. J. (Ed.): The Generation of Antibody Diversity: A New Look. Academic Press, New York, 1976; p. 127. 
12) KRETH H.W., Williamson A.R.: The Extent of Diversity of Antihapten Antibodies in Inbred Mice: Anti-NIP (4-Hydroxy-5-Iodo-3-Nitrophenacetyl) Antibodies in CBA/H Mice Europ. J. Immunol. 3, 141, 1973.

13) Kuettner M. G., Wang A. L., Nrsonoff A.: Quantitative Investigations of Idiotypic Antibodies. VI. Idiotypic Specificity as a Potential Genetic Marker for the Variable Regions of Mouse Immunoglobulin Polypeptide Chains - J. exp. Med. 135, 579, 1972.

14) Leder P., Honjo T., Serdman J., Swan D.: Origin of Immunoglobulin Gene Diversity: The Evidence and a Restriction-Modification Model - Cold Spr. Harb. Symp. quant. Biol. 41, $855,1976$.

15) Lydyard P. M., Grossi C. E., Cooper M. D.: Ontogeny of B Cells in the Chicken. I. Sequential Development of Clonal Diversity in the Bursa - J. exp. Med. 144, 79, 1976.

16) Nisonoff A., Fudenberg H.H., Wilson S.K., Hopper J.E., Wang A. L.: Individual Antigenic Specificity in Immunoglobulins: Relationship to Biosynthesis - Fed. Proc. 31, 206, 1972.

17) Pawlak L. L., Hart D. A., Nisonoff A.: Requirements for Prolonged Suppression of an Idiotypic Specificity in Adult Mice - J. exp. Med. 137, 1442, 1973.

18) Pawlak L. L., Hart D. A., Nisonoff A., Mushinski E. B., PotTer M.: Idiotypic Specificity and the Biosynthesis of Antibodies - In: Proc. 3rd Int. Convocation Immunol. May, 1972. S. Karger, Basel, 1973; p. 259.

19) Rabbits T.H., Jarvis J.M., Milstein C.: Demonstration that a Mouse Immunoglobulin Light Chain Messenger RNA Hybridizes Exclusively with Unique DNA - Cell 6, 5, 1975.

20) Richards F.F., Konigsberg W.H., Rosenstein R. W., Varga J.M.: On the Specificity of Antibodies - Science 187, 130, 1975.

21) Tomasz A.: Choline in the Cell Wall of a Bacterium: A Novel Type of Polymer-Linked Choline in Pneumococcus - Science 157, 694, 1967.

22) Tonegawa S., Hozumi N., Matrhyssens G., Schuller R.: Somatic Changes in the Content and Context of Immunoglobulin Genes - Cold Spr. Harb. Symp. quant. Biol. 41, 877, 1976.

23) Tonegawa S., Steingerg C., Dube S., Bernardint A.: Evidence for Somatic Generation of Antibody Diversity - Proc. nat. Acad. Sci. (Wash.) 71, 4027, 1974.

24) Tung A.S., Ju S.-T., Sato S., Nisonoff A.: Production of Large Amounts of Antibodies in Individual Mice - J. Immunol. 116, 676, 1976.

25) Ward K., Cantor H., Nisonoff A.: Analysis of the Cellular Basis of Idiotype-Specific Suppression - (Submitted for Publication).

26) Wu T.T., Kabat E. A.: An Analysis of the Variable Regions of Bence Jones Proteins and Myeloma Light Chains and Their Implications for Antibody Complementarity - J. exp. Med. $132,211,1970$.

Requests for reprints should be addressed to:

AlFRed Nisonofr

Rosenstiel Research Center, Department of Biology

Brandeis University

Waltham, Mass. 02154 - USA 